\title{
A colaboração em cursos de educação a distância: uma proposta construcionista social 1
}

\section{Vera Cecília Frossard, educação a distância, Escola Nacional de Saúde Pública Sergio Arouca, Fundação Oswaldo Cruz, (EAD/ENSP/Fiocruz), vera@ead.fiocruz.br}

\section{Resumo}

Vivenciamos hoje em dia na Internet um vibrante ambiente de colaboração na produção de informação, conhecimento e cultura. Este cenário é mais tímido quando o contexto é a educação a distância em processos formais de ensino. É comum cursos a distância se valerem de estratégias tais como o oferecimento de bônus e o incremento de notas para a promoção coletiva de saberes, o que acontece tão espontaneamente na comunidade internauta. O trabalho busca refletir o porquê desta diferença. O Construcionismo Social é aqui trazido como um aporte teórico relevante para a educação a distância, no incremento da co-construção de saberes e colaboração entre pares.

Palavras-chave: Construcionismo Social, Educação a distância, Colaboração.

\section{A Colaboração na Internet}

A Colaboração na Internet é espontânea. A internet se formou assim, colaborativamente: a maior parte dos softwares que gerenciam a Internet é de código aberto: "software livre" se refere à liberdade dos usuários executarem, copiarem, estudarem, modificarem, aperfeiçoarem e distribuírem o software. Outro exemplo deste espírito colaborativo na Internet são os RFC (Request for Comments), <http://www.rfceditor.org/>. Engenheiros de redes descrevem protocolos de rede e submetem à avaliação da comunidade mundial de rede. A votação determina se o protocolo será publicado. Estes dois exemplos de colaboração são os pioneiros na Internet. Hoje em dia, vivenciamos nova onda de colaboração, para além da categoria profissional dos informatas. Artistas, pesquisados, pessoas comuns, introduzem novas formas cooperativas de produção de informação, conhecimento e cultura, em oposição às

\footnotetext{
1 Trabalho adaptado de apresentação no XI Congresso Cread Mercosul. Educação, Saúde e Meio Ambiente, 22 a 24
} de agosto de 2007, Buenso Aires, Argentina. 
formas tradicionais de propriedade, baseadas em hierarquia e mercado. Indivíduos comuns tornam-se produtores de seu próprio ambiente informacional e cultural. Nunca houve uma mídia que lhes desse voz em larga escala. O resultado é um inovador processo de produção colaborativa de informação e cultura. Alguns acreditam que estamos diante de uma nova forma de produção de bens de informação como o advogado e professor da universidade de Yale, Yochai Benkler $<$ http://www.benkler.org/>. Yochai acredita que este é um comportamento com potencial de reorganizar o nosso espaço cultural e social, talvez até mesmo o econômico. Passamos de uma economia Industrial da Informação, caracterizada por poucos produtores de informação para muitos consumidores passivos, para uma economia interconectada da Informação, em que a produção é feita em colaboração e os consumidores participam desta produção (Benkler, Yokai, 2006).A Internet está plena de exemplos desta inovadora efervescência cultural. Vejamos apenas alguns exemplos:

○ Wikipédia, enciclopédia feita colaborativamente por milhares de pessoas. A enciclopédia atinge quase a marca de dois milhões de artigos publicados. Ela é gratuita, escrita em mais de 80 idiomas. Wikipédia é implementada pelo Wiki, um software livre que permite edição colaborativa para criação de textos.

○ Open Directory Project, 40.000 pessoas colaboram para criar um diretório ditado como o Yahoo, <http://dmoz.org/>.

○ Kuro5hin.org é um site sobre tecnologia e cultura, produzido colaborativamente pelos usuários da Internet.

○ O Everything2 é uma comunidade on-line sobre todo tipo de assunto, cultura, humor, tecnologia, poesia, ficção. Os textos são interligados aos outros por meio de palavras chaves designadas pelo autor. Os leitores também criam associações entre os textos em decorrência de sua leitura e acesso.

○ SETI@ home, voluntários oferecem a CPU do seu computador para a maior aplicação distribuída que existe, para busca de vida inteligente em outros planetas. As informações coletadas por meio de um radio telescópio são processadas em milhões de PCs dos voluntários.

○ Folding@ home, faz o mesmo para análise de resistência de drogas, para o tratamento de várias doenças. 
Contrariando os direitos autorais do autor, o movimento de informação livre e acesso universal, ganha cada vez mais adeptos. Pesquisadores aderem à idéia do copyleft. O copyleft preconiza a informação aberta: use-a, modifique-a, incorpora melhorias e disponibilize. Autores produzem seu trabalho com licenças que lhes garanta a autoria, mas a informação esta disponível na rede e sem custo para o público leitor. Licenças como GNU Free Documentation License ${ }^{2}$ da Free software Fundation e The Creative Commons Non-Commercial Share Alike License (CCNCSA), ${ }^{3}$ permitem que textos, apresentações e conteúdo de páginas na web sejam distribuídos e reaproveitados, mantendo, porém, o reconhecimento das autorias. Yokai Blenkler, autor já citado neste trabalho, oferece seu livro mais recente para download, The Wealth of Networks: How Social Production Transforms Markets and Freedom. Recentemente ele criou um site baseado na ferramenta de edição colaborativa de textos, Wiki, para que os leitores dos livros interferissem na escrita do livro original. ${ }^{4}$ Este é um interessante caso de escrita colaborativa que parece inaugurar um inovador modelo para produção de trabalhos científicos à moda do software livre: use, contribua, melhore, disponibilize. A livraria virtual Amazon, no entanto, vende o trabalho para quem estimar em ter o produto livro, original, com boa brochura e encadernação.

Outros exemplos de que o movimento da informação aberta ganha mais adeptos: cientistas da área médica lançaram em 2001 carta aberta sugerindo que publicações científicas fossem de acesso público, após seis meses da sua publicação. ${ }^{5}$ A carta ganhou milhares de assinaturas de cientistas. A idéia foi concretizada na criação da Public Library of Science (PLoS), site que abriga artigos de medicina e biologia com conselho editorial de especialistas adeptos da informação aberta e universal. ${ }^{6}$

Trabalhos colaborativos na Internet parecem indicar uma inovação com potencialidade de reorganizar o nosso espaço cultural e econômico. A educação tem amplo e fértil terreno a explorar tomando partido da colaboração entre pares e o efeito da construção

\footnotetext{
2 http://www.gnu.org/copyleft/fdl.html

$3<\mathrm{http}: / /$ creativecommons.org/>

$4<$ http://www.benkler.org/wealth_of_networks/index.php/Main_Page>

$5<$ http://www.publiclibraryofscience.org/>

6 <http://www.plos.org/about/>
} 


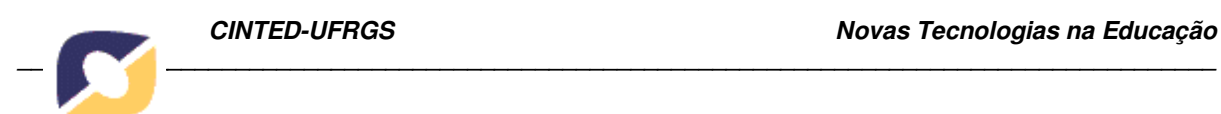

desta inteligência coletiva, distribuída, ativa, sinergicamente em interação por meio da rede

\section{A colaboração na educação a distância}

$\mathrm{O}$ aspecto formal da educação, no entanto, parece ser o impeditivo para o estabelecimento deste vibrante cenário de colaboração e construção de conhecimento: currículos previamente determinados, programas pré-estabelecidos, atividades inseridas em um sistema de avaliação, com respostas consideras melhores do que outras, prazos fixos, competências pessoais não exploradas. A colaboração na Internet é espontânea, permeada pela liberdade de escolhas, as pessoas dedicam suas competências específicas na construção conjunta de bens de informação sem ninguém dizer a elas em que deverão contribuir. Os blogs, as comunidades temáticas, construção conjunta de textos, sites de histórias e artigos são a expressão da liberdade de escolha. A meu ver é este o aspecto que limita a construção conjunta de conhecimento na educação. Romper com currículos pré-determinados envolve questões políticas, difíceis de resolução. A alternativa é criar espaços diferenciados daqueles formais, caracterizados por notas e avaliações, em que haja maior liberdade de expressão e criatividade na construção de novos e ampliados significados sobre a realidade, como acontece no ciberespaço.

A seguir, apresentamos o Constucionismo Social e sua aplicação potencial na educação a distância como suporte teórico para a criação desses espaços alternativos de colaboração.

\section{Construcionismo social}

O construcionismo social é um variado conjunto de definições teóricas, na psicologia social , estendendo-se para o campo psicoterapêutico. Para além das múltiplas acepções é possível extrair a seguinte idéia central (Gergen 1999): A realidade e o conhecimento são construídos a partir de interações humanas inseridas na linguagem, em um contexto histórico e cultural. A ênfase do construcionismo social é voltada para o modo como as pessoas criam significados próprios, em vez do modo como as pessoas conhecem os objetos e a realidade. É na linguagem e na prática social que o conhecimento é constituído (Gergen 1997). 


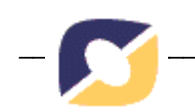

É na apropriação destas idéias no campo da psicoterapia, especialmente na terapia de grupo e familiar, que considero que os novos papéis atribuídos ao terapeuta e ao processo terapêutico têm relevantes contribuições para a educação na promoção de espaços de reflexão e colaboração. A educação e a terapia são contextos que se utilizam da linguagem, criando e orquestrando descrições, diz Maturana, citado por Cecchin (Maturana in Cecchin, 1989).

A seguir elenco as principais contribuições do construcionismo social para a educação a distância:

1) Foco no significado: o construcionismo leva em consideração os significados particulares que as pessoas constroem e que balizam sua vida, e os novos significados construídos no processo de aprendizado (terapia). A idéia precípua do construcionismo social de que não há um único e verdadeiro questionamento sobre a realidade e sim variadas formas, tem como efeito o estabelecimento de um contínuo processo de significação. O recontar de uma narrativa produz outra, com aspectos da antiga narrativa porém ampliada. Este é o importante aspecto dialógico do aprendizado (White \& Epson, 1990, p.32). Cada comentário tem uma lógica, tem significados próprios. Perguntar sobre eles pode enriquecer o diálogo (Cecchin, 2004, p.20). Cecchin observa que o terapeuta (professor) deve manter em alerta sua curiosidade pela fala do outro, inquirindo a fala como algo novo, do qual não ouviu falar. Novos significados surgem ou são ampliados a partir deste interesse pela fala do outro. Cecchin propõe que perguntas circulares sejam feitas, como método de manter o terapeuta (professor) em constante postura de curiosidade, convidando o indivíduo a refletir sobre suas idéias. Acredita ele que podemos observar conseqüências interessantes originárias de um contexto interrogativo, em que se abandonam "verdades" rígidas, caracterizadas pelo verbo ser "a realidade é assim", para ênfase nas relações. "Isso faz com que as coisas circulem" (Cecchin, 1996), pois as idéias conectam-se umas às outras. A partir de perguntas circulares, as hipóteses dos alunos ganham em amplidão e complexidade analítica. (Cecchin, 2004, p.25). Estas perguntas circulares começam com "se" e se direcionam para o futuro e situações hipotéticas. Por exemplo: Se acontecesse tal fato, como a sua descrição sobre tal coisa ficaria? No momento em que uma pergunta sacode 
o sistema de crenças, cria oportunidade para novas narrativas e as explicações ganham em dimensão: "se somos curiosos, questionamos as premissas, nossas próprias e as dos outros." (Cecchin, 2004, p.25)

Neste ponto observamos que o professor é um facilitador de um processo de construção do conhecimento. Vamos ao segundo ponto do Construcionismo social o qual gostaria de destacar, o novo papel para o terapeuta. As analogias para o professor são perfeitamente cabíveis:

2) Foco nos processos terapêuticos (educacionais) como co-construção: o terapeuta (professor) não adota postura de especialista A responsabilidade do professor é criar um contexto de colaboração através do qual seja possível estabelecer reflexões que levem a significados ampliados ou novos. Desta maneira promove-se nova dinâmica de relacionamentos entre professor e alunos caracterizada por colaboração na produção de sentidos e não por mecanismos de hierarquia. De um lado, a participação do professor neste processo dialógico da-se como um observador participante que busca por meio de uma posição igualitária e não hierárquica construir colaborativamente com os outros, de outro lado, como facilitador, ele busca promover e sustentar a conversa. Ele considera e trabalha com todas as visões surgidas (Anderson \& Goolishian, 1988), mantendo a sua postura de curiosidade (Cecchin, 1996).

Vejamos a seguir uma método relevante para o estabelecimento deste espaços alternativos de reflexão:

3) Foco em processos reflexivos: Quando pessoas compartilham seus pontos de vista, cada uma recebe da outra diferentes versões da realidade (Andersen, 1987). Os processos reflexivo são trocas entre o falar com os outros sobre vários assuntos e o sentar e escutar os outros a falarem sobre os mesmos assuntos. A fala com os outros é uma fala externa. Aquela que a pessoa tem consigo mesma (quando escuta a fala dos outros) é uma fala interna. Estes dois tipos de fala parecem tratar o mesmo assunto de uma maneira diferente. $\mathrm{O}$ que acontece na fala externa será uma perspectiva para a fala interna e vice-versa. Perspectivas múltiplas sobre o mesmo assunto criarão novas idéias 


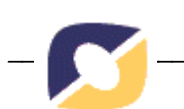

e significados. Uma versão diferente influencia a atitude de uma pessoa em relação a este mundo, e o torna diferente do que ele era antes. (Andersen, 2004). Na terapia de família, esta técnica tem sido bastante empregada por meio da equipe reflexiva: um grupo de terapeutas assiste a conversa entre a família e os terapeutas de campo, em silêncio. Em algum momento eles são convidados a emitirem idéias sobre o que se passou na sessão ate aquele momento. A família tem a oportunidade de experimentar a fala interna, escutar em silêncio a equipe reflexiva. Ambas as falas são propiciadoras de construção de novos significados. A educação a distância pode se valer destes espaços reflexivos, da fala externa, em que os protagonistas da discussão se expressam, e a fala interna, em que ouvem em silêncio idéias sobre seu debate. A turma pode ser dividida em grupos para que um deles desempenhe o papel de equipe reflexiva. Ou todos podem exercitar os dois tipos de "fala", em que se exercita o falar e o comentar a fala dos colegas.

4) Foco na diferença que faz diferença: considerando a interessante definição de Bateson sobre informação, "Informação é uma diferença que faz diferença”, Tom Andersen diferencia três tipos de diferença: a primeira é uma diferença muito pequena para ser notada pelo aluno; a segunda é uma diferença considerável, ela é grande demais para ser notada; a terceira é uma diferença grande demais e pode ter um efeito desorganizador no sistema. Em tais casos, o sistema geralmente se fecha para aqueles que tentariam implementar tal diferença (Andersen, 1987).

A partir destas considerações, surgiram algumas diretrizes para o trabalho do professor: Atividades alheias às realidades dos alunos, que não levem em conta suas competências pessoais, suas singularidades, seu tempo, podem gerar um sistema paralisado (considerado neste contexto educacional aquele em que não há interação na construção de novos significados). Isto é, um sistema cuja informação não fez diferença, ou porque é grande demais para ser alcançada ou porque é pequena demais para ter valoroso significado.

Cursos a distância correm este risco, de não levarem em conta as realidades locais, separadas dos grandes centros produtores de conhecimento. O professor deve estar 
atento a perceber informações que fazem diferença para a turma e convidá-los a formarem comunidades de discussão ou outra proposta de interesse dos alunos. O professor, sensível ao processo de comunicação dos alunos, não deixa que perguntas, reflexões e comentários que fazem diferença, fiquem sem contribuições. Os demais alunos são convidados a comentar idéias originais que tenham potencial de desdobrar-se em significados ampliados sobre temas. O professor facilitador dirige seu olhar para o processo de comunicação, mais do que para o conteúdo. Exemplo de perguntas que enfocam o processo:

1- Solicitar que sejam destacadas as idéias relevantes para a prática profissional de cada um, a partir dos temas abordados e debatidos.

2- Perguntar que idéias os alunos não concordam ou sentem-se distantes?

3- Que outras idéias lhes ocorrem?

4- $\mathrm{O}$ aluno considera que sua participação em uma nova conversa sobre o tema seria diferente? De que maneira?

Estas são apenas sugestões de perguntas que convidam a comunidade a refletir. Outras perguntas que ampliam discussões sobre o tema podem ser sugeridas pelo professor facilitador.

\section{Considerações}

O mundo é construído pelos seres humanos e não descoberto por eles como se houvessem verdades a desvelar. Esta concepção é particularmente interessante na educação pois convida cada pessoa a refletir sobre sua responsabilidade ética na construção de novos significados sobre a realidade. "Qualquer coisa que inventamos é de nossa responsabilidade". (Foster, 1991, p.126). O conhecimento traz conseqüências sociais e este é o termômetro para considerá-lo valido ou não (Gergen 1999). Há profunda Interligação entre conhecimento e ação bem como valorização de uma postura critica e reflexiva. Estes pressupostos parecem valiosos para uma concepção pedagógica voltada para a noção de que o aluno constrói o próprio conhecimento. Esta asserção é mais exitosa se o aluno depara-se com possibilidades de exercer liberdade para uso de suas competências pessoais. O professor, um "curioso" sobre o discurso dos alunos, 
busca conhecer os significados próprios e particulares de cada aluno, convida a turma a refletir e expor idéias e significados. Dessa maneira são fornecidos os elementos que facilitam a prática da colaboração e co-construção de novos e ampliados significados sobre a realidade.

\section{Bibliografia}

ANDERSEN, Tom. A linguagem não é inocente. Perspectivas Sistêmicas, Rio de Janeiro, n. 23, p. 22, 2004.

Family Process, n.26, p. 415-428, 1987, MA, USA.

ANDERSON, Harelene \& Goolishian, Harold A., Human Systems as linguistic System: preliminary and evolving ideas about implications for clinical theory, Family Process, n. 27, p. 371-393, 1988, MA, USA.

BENKLER, Yochai, The Wealth of Networks, How Social Production Transforms Markets and Freedom, Yale University Press, 2006.

Disponível em <http://www.benkler.org/wealth_of_networks>. Acesso em: 02/05/2007

CECCHIN, Gianfranco, Preconceitos Sistêmicos. Entrevista à Cláudio Champs.

Perspectivas Sistêmicas, Rio de Janeiro, Outubro/Novembro, 1996.

Clássicos da terapia da família: nova visita à hipotetização, à circularidade e à neutralidade: um convite à curiosidade. Perspectivas Sistêmicas, Rio de Janeiro, n. 24, 2004.

FOSTER, H. V. Las Semillas de la Cibernética. In: PAKMAN, M. (Org.) Coleccion Terapia Familiar, Obras Escogidas, ed. Gedisa, 1991.

GERGEN, K. J \& AARHUS, L., la terapia como una construccion social dimensiones, deliberaciones, y divergencias.

Disponível em 
$-C$ CINTED-UFRGS Novas Tecnologias na Educação

$<$ http://www.swarthmore.edu/SocSci/kgergen1/web/page.phtml?id=manu18\&st=manus cripts\&hf=1>. Acesso em: 10/07/2007.

, An invitation to social construction. Sage, Londres, 1999.

White, M., \& Epston, D. Medios narrativos para fines terapeuticos. Buenos Aires:

Paidós, 1990. 